\title{
Reflexões Estratégicas sobre o Composto Promocional de Marketing no Contexto da Internet. Um Estudo Exploratório junto a uma Instituição Financeira
}

\author{
Luciano Augusto Toledo \\ Sidney Maçazzo Caigawa \\ Thiago J. Rocha
}

\begin{abstract}
RESUMO
O presente trabalho, por meio da interdisciplinaridade da Internet e Marketing, foi desenvolvido com o objetivo de fornecer uma análise de algumas das implicações da utilização do ferramental Internet no composto promocional de marketing de uma instituição financeira. $\mathrm{O}$ trabalho apresentase sob a modalidade de pesquisa exploratória, complementado empiricamente por um estudo de caso, e se compõe de uma revisão do referencial teórico, mediante análise conceitual crítica de alguns aspectos do assunto Internet e marketing. A Pesquisa exploratória concentrou-se na aplicação de um roteiro de perguntas aos responsáveis pela gestão de marketing no âmbito das ações de promoção e Internet na instituição estudada. Como resultado da pesquisa, chegou-se à conclusão de que a Internet é fundamental no composto promocional de marketing do Banco do Brasil.
\end{abstract}

Palavras-chave: comércio eletrônico; Internet; promoção; marketing.

\begin{abstract}
The present study describes the interdisciplinary between Internet and Marketing discipline and was developed to provide an analysis of the Internet implications on the promotion marketing mix. The study is developed under the modality of exploratory research, complemented by a case study, and it is composed by a bibliography revision, a critical conceptual analysis of some pertinent aspects of the Internet and Marketing discipline. The exploratory survey was based in an interview guidebook used with the marketing staff. The result of the research was that the Internet is an important component in the promotion marketing mix of the Banco do Brasil.
\end{abstract}

Key words: electronic commerce; internet; promotion; marketing. 


\section{INTRODUÇÃO}

Em um mundo globalizado, caracterizado pela forte concorrência, a informação torna-se grande diferencial; a empresa que melhor utilizar a informação disponível mais apta estará para realizar ajustes em suas estratégias. Nesse contexto, a Internet constitui fonte de informação muito rica. Torna-se oportuno afirmar que a Internet está gerando transformações no modo de pensar e agir de alguns setores da sociedade, propiciando a criação de novas estratégias cuidadosamente desenhadas para a conquista dos mercados e clientes virtuais, a melhoria da eficiência nos processos gerenciais e o aumento de eficácia na consecução dos objetivos (Drucker, 2000).

Muitas empresas estão reconhecendo a importância da utilização da Internet. As possibilidades de utilização dessa nova mídia como novo canal de comunicação com clientes ou mesmo como novo canal de distribuição e mídia alternativa de propaganda, está começando a ser compreendida. Algumas empresas como, por exemplo, Lojas Americanas e o Shoptime, têm utilizado seus portais eletrônicos (www.americanas.com.br e www.shoptime.com.br) como novo canal promocional e de distribuição de seus produtos. Outras empresas decidiram migrar totalmente para o ambiente virtual da Internet, reduzindo seus intermediários e concentrando forças na fidelização de clientes e agilidade na distribuição. É o caso do www.dell.com e www.netflores.com.br, empresas que virtualizaram (só existem virtualmente) suas lojas e as transformaram num portal eletrônico de compra e venda de produtos, funcionando sete vezes por semana, vinte e quatro horas ao dia e trezentos e sessenta e cinco dias ao ano.

Assim como o mundo, o Brasil também passa por uma popularização do uso da Internet. A expansão das linhas telefônicas, a sofisticação e o barateamento dos artigos de informática e o surgimento dos provedores gratuitos e das novas tecnologias de acesso contribuem para explicar a aceitação crescente da Internet pelos consumidores como nova forma de se comunicar, buscar informações, comprar produtos e serviços ou apenas se divertir. De acordo com estudo realizado pela empresa E-consulting, o número de usuários de Internet no mundo (pessoas física e jurídica), totalizou 825 milhões, no ano de 2003. Só nos EUA, 187 milhões de pessoas acessaram a Internet no ano de 2003. Na América Latina os internautas já são 44 milhões. Embora o Brasil tenha o maior número absoluto de internautas, a taxa de penetração ainda é baixa (cerca de 9,8\%), se comparada à de outros países da mesma região, como o Chile (cerca de 15\%) e a Argentina (cerca de 12\%). Ainda segundo o mesmo estudo, os internautas no Brasil 
totalizaram 17,4 milhões em 2003, número 21,7\% superior ao registrado no ano de 2002 e a tendência esperada para 2004 é que o número de internautas brasileiros atinja 20,9 milhões, na América Latina 58 milhões, nos EUA 193 milhões e no mundo 945 milhões.

Conforme Albertin (1998), as instituições financeiras vêm-se reestruturando para criar um banco virtual, baseado no auto-atendimento. Primeiro vieram os terminais de auto-atendimento, permitindo que os bancos pudessem ampliar a capacidade de atendimento aos clientes e reduzir o número de funcionários. Em seguida, cresce a popularização do uso do Office-banking e desse ponto nasce o home-banking, já voltado para as pessoas físicas, mas utilizando software proprietário. Ainda segundo o mesmo autor, o e-banking surgiu como evolução natural do home-banking, mas representando uma nova alternativa de baratear custos por meio de auto-atendimento, dispensando a necessidade de o cliente se deslocar até o banco. As aplicações de Internet estão mudando a interação de bancos, consumidores e concorrentes (Albertin, 1998). Dessa forma é pertinente uma analise das implicações da utilização do ferramental Internet como facilitador de negócios e como canal promocional, principalmente.

\section{Metodologia}

O objeto de estudo deste trabalho é as implicações da utilização do ferramental Internet no âmbito do composto promocional de marketing; para isso foi escolhido o método de estudo de caso. De acordo com Bonoma (1985), o estudo de caso é descrição de uma situação gerencial, que envolve um ciclo de revisão de teoriadados-teoria, o que o torna passível de ser utilizado na situação da instituição financeira Banco do Brasil.

Farina (1997) observa que a elaboração de um estudo de caso deve ser feita em estreita colaboração com a instituição objeto de estudo, visando apresentar uma situação problema que exija tomada de decisão, pois é necessário o levantamento de dados que somente serão obtidos na empresa pesquisada. No caso do Banco do Brasil, o instrumento utilizado para coleta de dados foi um roteiro seguido de entrevista, com questões abertas, considerada como investigação semi-estruturada. A entrevista foi realizada em uma única etapa, na qual o entrevistador aplicou um questionário aos profissionais responsáveis pela gestão de marketing e de Internet. A aplicação do instrumento foi sempre no local de trabalho dos respondentes, em situação discreta e confidencial e com duração média de aproximadamente 30 minutos. 


\section{Referencial Teórico}

\section{Internet}

Laudon e Laudon (2004) dizem que a Internet é, talvez, a maior e mais conhecida implementação de redes interligadas. Uma rede que permite manter conectadas centenas de milhares de redes individuais ao redor do mundo todo, fornecendo acesso on-line vinte e quatro horas, sete dias da semana e trezentos e sessenta e cinco dias do ano, para seus usuários. A tecnologia de Internet abriu uma variedade de oportunidades, as quais estão sendo utilizadas pelas empresas, para a troca de informações internamente, e para se comunicarem externamente com outras empresas, criando uma plataforma universal para a compra de bens e serviços, ou para dirigir importantes processos de negócios dentro das empresas. Com tais aplicações, a Internet tende a tornar-se, em particular, um expressivo catalisador tanto do e-commerce como do e-business.

Bransky (1999) define o comércio eletrônico como a ação de compartilhar informações, manutenção de relacionamentos e condução de transações de negócios por meio de redes de telecomunicações dentro e fora das empresas. Assim, o comércio eletrônico é a maneira pela qual vendas e compras são geradas, suas concretizações e a ações de marketing de pós-venda, tudo isso realizado on-line. Ainda segundo o mesmo autor, a Internet é ferramenta de inegável importância no comércio eletrônico, uma vez que possui uma tecnologia de fácil entendimento, possui domínio público: qualquer pessoa, em qualquer lugar, pode acessá-la, bastando para isso um computador e uma linha telefônica. Essa facilidade passou a orientar as empresas quanto à venda ao cliente final, sem a necessidade de investimentos vultosos, criando grande interesse em número cada vez maior de setores econômicos.

Com a Internet, a pessoa ou empresa interessada em comprar ou vender algo, pode interagir na busca de informações de seu interesse, e não precisa limitar-se ao que lhe é apresentado inicialmente. Seguindo as perspectivas que se abrem com a customização de massa, a tecnologia de Internet permite hoje, a baixo custo, um nível cada vez mais significativo de personalização dos serviços e do atendimento (Chleba, 2000). Um exemplo é o das empresas de logística, como os Correios e a Federal Express, em cujos websites cada cliente pode acompanhar detalhadamente a localização e o trajeto de sua encomenda. Outros exemplos são os websites, como o Yahoo, dentre outros, que permitem ao usuário configurar o seu website, isto é, os elementos do website que deseja que lhe sejam apresentados, quando estiver conectado. 
Conforme observa Albertin (1998), o comércio eletrônico é a realização de toda a cadeia de valor dos processos de negócio num ambiente eletrônico, por meio da aplicação intensa das tecnologias de comunicação e de informação. Os processos podem ser realizados de forma completa ou parcial, incluindo transações business to business (B2B), business to consumer (B2C) e intra-organizacionais. Assim, o comércio eletrônico abrange qualquer negócio transacionado eletronicamente, entre dois parceiros, ou entre um negócio e seus clientes. Por essa linha, o importante é o conhecimento justamente sobre esses parceiros de negócio. Muitas empresas ainda operam como se estivessem sozinhas no mundo, sem estabelecer processos permanentes de gestão do seu conhecimento sobre a concorrência, o mercado e os clientes. Os principais tipos de atividades do comércio eletrônico podem ser estabelecidos da seguinte forma: entre as próprias empresas (B2B ou business to business), entre a empresa e o mercado consumidor (B2C ou business to consumer), entre consumidor e as empresas ( $\mathrm{C} 2 \mathrm{~B}$ ou consumer to business), entre consumidores (C2C ou consumer to consumer) (Telles, 2003).

O primeiro tipo de atividade (B2B) ocorre entre fornecedores e varejistas que, por meio da troca de informações digitais, controlam melhor os estoques, a distribuição e os pagamentos. As empresas ampliam geograficamente seus mercados, mas devem considerar a exigência de uma infra-estrutura computacional e de comunicação de dados adequada, além de logística e segurança. No Brasil as transações econômicas decorrentes do B2B pela Internet movimentaram no ano de 2003, aproximadamente 36,7 bilhões de reais.

No segundo tipo de atividade (B2C), a empresa torna disponíveis ao consumidor informações detalhadas e visualizadas digitalmente sobre seus produtos, a venda desses produtos sem necessidade de intermediação e a possibilidade de efetuar o pagamento de forma eletrônica. A entrega do produto também pode ser feita utilizando-se a Internet, como, por exemplo, a entrega de um software por meio de download. Conforme a e-consulting, o B2C no Brasil movimentou 5,2 bilhões de reais no ano de 2003. No terceiro tipo de atividade (C2B), o consumidor torna-se uma voz ativa no processo de compra de produtos ou serviços pela Internet. É o cliente definindo como deseja ser atendido, a que preço e de que forma. No quarto tipo de atividade (C2C), busca-se uma participação conjunta de todos os consumidores; é o caso dos leilões virtuais. Tem-se, a partir daí, uma melhora na comunicação entre as pessoas físicas, visando ao desenvolvimento dum mercado sem intermediários e de fácil negociação.

Mais recentemente, o governo passa a participar do Comércio Eletrônico pela Internet, para promover maior transparência de suas atividades, e permitir o exercício da cidadania pelos membros da sociedade. O E-government implica as relações estabelecidas entre os governos e as empresas (G2B ou government 
to business), entre os governos ( $\mathrm{G} 2 \mathrm{G}$ ou government to government) e entre os governos e consumidores ( $\mathrm{G} 2 \mathrm{C}$ ou government to consumer).

\section{Conceitos de Marketing}

Na definição de Kotler e Armstrong (2002), marketing é o processo social e gerencial por meio do qual indivíduos e grupos obtêm aquilo de que necessitam e desejam.

Para Cobra (1993), algumas pessoas relacionam marketing apenas com propaganda ou com venda. Ainda, segundo o autor, o marketing é mais do que propaganda ou venda simplesmente. O marketing, ao integrar forças para colocar o produto certo no local certo, é mais do que um exercício de negociação entre produtores e distribuidores: é uma filosofia de trabalho, em que todos na empresa devem refletir e agir sob a ótica do marketing.

El-Check (1991) afirma que o marketing é a ciência que trata do conjunto de atividades voltadas para a satisfação das necessidades e desejos dos consumidores, sejam eles indústrias ou pessoas; ou de outra forma: é o processo de inteligência dentro da empresa, na função básica de preparação das estratégias de condução dos negócios. De acordo com Cobra (1993), marketing é uma expressão anglo-saxônica derivada da palavra mercari, do latim, que significa comércio, ou ato de mercar, comercializar ou transacionar.

Para Morris (1991), o objetivo do Marketing é descobrir o desejo do cliente e satisfazê-lo para obter lucro. É o oposto de fazer o que o empresário gosta e então procurar alguém para comprar. $\mathrm{O}$ bom marketing pretende facilitar a obtenção de vendas lucrativas, enquanto o mau torna-as impossíveis. McDonald e Dunbar (1995) afirmam que é vantagem para as empresas terem conhecimento das necessidades de seus clientes, pois esta seria a chave para o sucesso da gestão do marketing. Conforme Kotler (2002), o marketing é relevante tanto para os mercados industriais como para os de consumo final; tanto para os de indústrias de serviços como para os de indústrias de bens; tanto para pequenas como para grandes empresas; tanto para empresas que não visam ao lucro como para aquelas que visam a ele; e tanto para compradores como para vendedores.

\section{Composto de Marketing (Marketing Mix)}

O composto de marketing, segundo Waterschoot (1992), foi introduzido por Neil Borden em 1953, com base no trabalho de James Culliton. Para Culliton como citado em Waterschoot (1992), o gestor de negócios era alguém que combinava diferentes ingredientes. Desse momento em diante, a expressão 
Composto de marketing assumiu a conotação de composição de ingredientes para obtenção de uma resposta do mercado.

Vários autores utilizam uma lista de variáveis (variáveis controláveis de marketing) ou ferramentas, e de atividades relacionadas a elas para facilitar a explicação do conceito de composto de marketing. Dessa forma, para McCarthy (1996), o composto de marketing compreende decisões que a empresa precisa tomar sobre as variáveis controláveis, com o intuito de atingir o mercado-alvo. Ainda segundo o mesmo autor, para organizar e simplificar as decisões, as variáveis controláveis de marketing podem ser divididas em quatro grupos conhecidos como os quatro P's do marketing: Produto, Preço, Promoção e Praça (Distribuição), conforme Figura 1.

\section{Figura 1: Os 4 P's do Composto de Marketing}

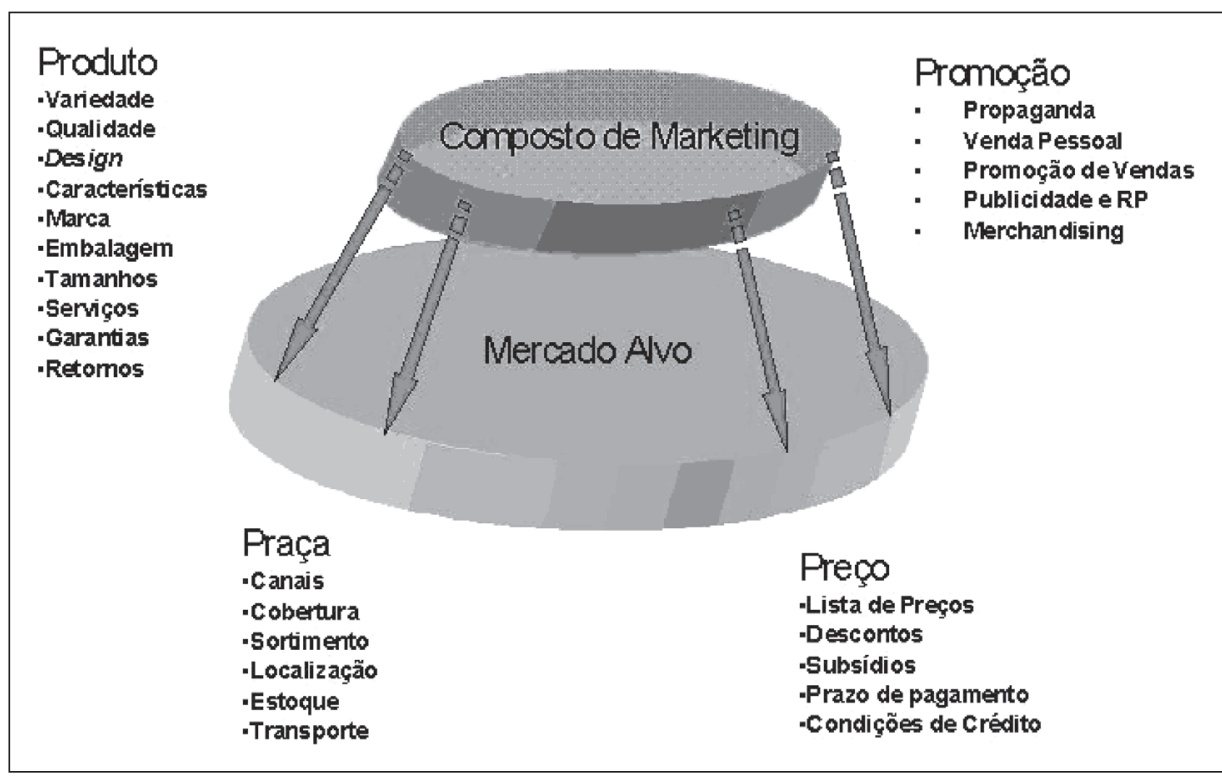

Fonte: adaptado de Kotler, (2002).

Kotler (2002) considera o Composto de Marketing como um conjunto de ferramentas de marketing que a empresa utiliza para perseguir seus objetivos de marketing no mercado alvo.

\section{A Internet e o Marketing}

Para Laudon e Laudon (2004), a Internet é um ferramental poderoso para vendas e marketing, pois fornece capacidades para a personalização e interação com clientes que não podem ser encontradas em outros canais. Empresas podem 
manter diálogos continuados com clientes, usando e-mail, bate-bapo e grupos de discussão eletrônica, para solidificar seus relacionamentos com eles.

Silva e Oliveira (1997) afirmam que o marketing na Internet difere do marketing tradicional, porque, no primeiro caso, as empresas buscam definir e atingir seu mercado-alvo, já na Internet são os clientes e os prospects que se dirigem aos websites das empresas. Para os autores, como conseqüência da globalização, os produtos (bens e serviços) podem ser criados e produzidos em diferentes localidades, cabendo às empresas o papel da busca pela expansão do conceito de produto, pela Internet, por meio dos serviços de atendimento ao consumidor e de pós-vendas. O Preço, que depende da percepção de valor do produto pelo cliente, passa a ter seu foco sobre os meios de pagamento e as questões legais e de segurança nas transações, refletindo os custos de produção e distribuição na Internet. A Praça ou Distribuição expande-se para o espaço virtual da própria Internet, na busca pela distribuição de produtos on-line, em qualquer tempo e lugar. A Promoção ou Comunicação passa a ser uma nova mídia, com caráter de interatividade.

\section{A Internet e a Estratégia de Produto}

Uma das importantes contribuições da Internet às decisões de Produto parece ser a maior facilidade de customização, ou seja, oferecem-se ao consumidor condições de solicitar um produto feito especialmente para ele, respeitando suas especificações, de maneira mais ágil. É o caso, por exemplo, da Closet.com.br, a primeira camisaria digital sob medida do Brasil, onde o consumidor pode escolher vários tecidos, cores, colarinhos, bolsos e montar sua própria camisa, de acordo com suas medidas. Em alguns casos, o número de combinações possíveis é expressivo, e a tecnologia pode facilitar a simulação ou a escolha delas, em tempo real. A tecnologia da Internet também permite que os catálogos eletrônicos sejam atualizados dinâmica e rapidamente (Kosiur, 1997). Empresas que não oferecem produtos customizáveis muito provavelmente perderão espaço para outras que têm condições de oferecer ao consumidor a liberdade de montar um produto personalizado.

Exceto pelos novos produtos em formato digital, como músicas, livros, softwares, e alguns serviços, a abordagem às decisões relacionadas aos produtos não necessariamente mudou em relação às práticas tradicionais; acrescentaram-se, talvez, alguns aspectos, como, por exemplo, segurança e privacidade das informações fornecidas, rapidez em download, que nem sempre dependem apenas do website. No entanto, uma vez que o produto comercializado pela Internet não pode ser tocado nem provado no ato da compra, que as cores visualizadas no monitor do computador provavelmente não são exatamente iguais 
às originais, e que os sistemas de simulação de odores ainda se encontram em seus estágios iniciais, o que mudou com a utilização da Internet como ferramenta comercial de suporte às decisões sobre produtos foi a possibilidade de proporcionar incremento de seus atributos para os clientes, diferenciando-os e tornando a sua seleção uma experiência atrativa e vantajosa.

\section{A Internet e a Estratégia de Praça (Distribuição)}

Segundo a primeira versão dos 4P's de McCarthy (1996), a Praça está relacionada a onde, quando e por quem o produto seria comercializado. Praça, portanto, envolve decisões sobre canais de distribuição, sortimento, localização de lojas, estoque e transporte de produto. Las Casas (1992) considera o aspecto da praça como uma das decisões mais importantes na estratégia dos 4P's. Segundo o autor, o ponto-de-venda (praça) deve estar em uma posição estratégica que considere os consumidores e a concorrência.

$\mathrm{Na}$ Internet, a loja resume-se no espaço da tela do monitor do computador. Os endereços das lojas também são parecidos. Começam com um www (ou um http://www) e terminam com um .com ou .com.br. Pontos valiosos em ruas movimentadas estão sendo trocados por um hyperlink em portais com intenso tráfego.

A Internet proporciona algumas inovações relativamente ao $\mathbf{P}$ de Praça. A primeira delas é o boom de desintermediação, em que o fabricante passa a vender diretamente para o consumidor final, seja no caso de um produto simples como sapato, ou de produtos mais complexos, como seguros de vida ou computadores. O processo de desintermediação provoca a revisão de alguns subsistemas do setor varejista e acrescenta novos desafios para o fabricante que decide vender diretamente ao consumidor final.

Por outro lado, Windham (1999) lembra que a Internet criou oportunidades para o surgimento de outros tipos de intermediários. São empresas que oferecem vendas ou serviços de conteúdo, tornando a condução de negócios na Internet mais fácil, identificando oportunidades e preenchendo lacunas criadas pela Internet. Os benefícios aos clientes incluem assistência na busca e avaliação de produtos e serviços, avaliação de necessidades e busca de produtos adequados, redução de risco, e entrega ou distribuição de produtos. Já os benefícios aos produtores dos websites incluem a criação e disseminação de informações sobre os produtos, criação de consciência sobre o produto, influência na compra dos clientes, fornecimento de informações sobre os clientes, redução da exposição ao risco e redução de custos de distribuição por intermédio de economias de escala de transações. 
No entanto alguns segmentos do mercado não podem eliminar completamente os intermediários por meio de websites. Para os gestores de marketing, uma séria limitação presente no sistema de distribuição parece ser a entrega dos produtos ao consumidor final. A despeito dos avanços propiciados pela Internet, o custo da logística talvez seja um dos gargalos a serem superados. Assim é que, no Brasil, empresas de entregas rápidas, assim como os correios, estão sendo bastante requisitadas. Entretanto, o custo do frete está sendo repassado para os clientes. Dessa forma, pode-se supor que o comércio pela Internet torna disponível uma poderosa ferramenta de distribuição, desde que haja logística e distribuição física competente, com prazos e condições aceitáveis. Além disso, uma logística eficaz requer um gerenciamento adequado da cadeia de fornecimento, o que envolve a integração, desde os fornecedores de matérias-primas, passando pelo processo de produção e chegando à movimentação física dos bens produzidos até os clientes (Boone \& Kurtz, 2001).

\section{A Internet e a Estratégia de Preço}

As decisões de preço são decisivas para o alcance dos resultados econômicos e financeiros, para o posicionamento estratégico competitivo da empresa, para a consecução de objetivos relacionados a volume de vendas e a prestígio (Boone \& Kurtz, 2001).

Conforme Turban (2000), dentre os vários modelos de precificação utilizados na Internet, destacam-se:

- Dinâmica: trata-se de um mecanismo que concilia oferta e demanda por meio de uma estrutura de preços, o qual é utilizado para troca de ações e em mercados de commodities. Há outros exemplos: pedidos de pizza on-line nos horários das refeições, os quais poderiam ser cobrados a um preço superior ao dos pedidos feitos em horário de menor movimento.

- Variável: esse recurso objetiva gerar vendas e receitas incrementais, pela variação do preço de um item. Um produto, a título de experimentação, pode ser oferecido com desconto, para então ser vendido ao preço inicialmente determinado, depois de aprovado. Ou podem ser oferecidas várias versões de um mesmo bem ou serviço, a preços variados, ou até mesmo pode existir a variação de preço em função da perecibilidade. É o que ocorre, por exemplo, com a venda de assentos vagos de avião pela Internet, à medida que a data do vôo se aproxima, em vôos pouco concorridos. No entanto a precificação variável não é aplicável a qualquer situação, principalmente em casos em que a demanda do produto/serviço tende a ser estável, o que possibilita sua previsão com bom nível de precisão, não caracterizando, dessa forma, o 
elemento perecibilidade. Questões éticas e relacionadas a direitos do consumidor dificultam tais práticas, como a Amazon.com descobriu, quando teve que devolver a diferença paga por seus clientes, após oferecer o mesmo DVD com preços diferenciados.

Laudon e Laudon (2004) lembram que a Internet ampliou o poder de barganha do consumidor, ao possibilitar o surgimento de quatro poderosas ferramentas, aqui explicitadas.

1. Comparação instantânea de preços: consumidor pode verificar o preço do bem que deseja comprar em várias lojas digitais, simultaneamente, e escolher o menor preço disponível.

2. Leilão reverso: essa ferramenta possibilita a realização de leilões pelo valor menor ao contrário do leilão tradicional. Websites de leilão como bcomb.com.br ou MercadoLivre.com.br são exemplos de empresas que oferecem este tipo de serviço pela Internet.

3. Mecanismo 'defina seu preço': O consumidor define o preço que deseja pagar por uma mercadoria ou um serviço, e o website busca fornecedores que atendam o consumidor.

4. Grupos de compras: Consiste na criação de grupos de consumidores interessados na aquisição do mesmo bem e negociam com vários fornecedores, obtendo menores preços.

Embora estes sistemas de compra sejam encontrados há bom tempo no mundo físico, a Internet facilitou a compra e a negociação de preços, em muitos casos com a vantagem de, além de obter a informação da comparação, o cliente poder fazer seu pedido a partir de seu próprio computador.

Al Ries como citado em Bottini (2000) acredita que, no curto prazo, a Internet será principalmente um local para descobrir preços baixos e uma qualidade de serviço mais personalizado. Daí a necessidade de controle dos custos de fabricação e comercialização para que não se opere com preços abaixo do ponto de equilíbrio. Uma tática importante para manter ou aumentar as margens de lucro é a oferta de produtos customizados, artifício que dificulta a comparação instantânea de preços. Boone e Kurtz (2001), no entanto, tendo em vista a existência de mecanismos que facilitam a comparação instantânea de preços, acenam com a tendência de padronização deles, que não serão necessariamente baixos. Os compradores on-line podem comparar características e preços à vontade, sem serem pressionados por um vendedor, ou restritos aos horários de operação ou a certos limites geográficos. 


\section{A Internet e a Estratégia de Promoção}

Segundo Bishop (2000), a promoção por meio da Internet é mais racional do que emocional, o que implica um processo de persuasão e não apenas de informação, o que pode variar, evidentemente, conforme o tipo de produto ou serviço. Ainda segundo o mesmo autor, as ações promocionais têm os seguintes objetivos: fornecer informações para consumidores e outros interessados, aumentar a procura, diferenciar um produto ou serviço, incrementar valor de um produto ou serviço, estabilizar as vendas.

Para Limeira (2003) com a utilização do ferramental Internet, o composto promocional é afetado diretamente ao âmbito do marketing direto. A Internet representa um canal adicional para obtenção de informações de produtos e serviços pelos consumidores, mas também para a elaboração de programas de relacionamentos e estratégias de marketing. Com a utilização da Internet, as vendas pessoais passam a ser efetuadas por meio de links interativos da empresa com o comprador, e se este assim desejar, sem a intervenção de um vendedor.

Com o advento da utilização da Internet como mídia eletrônica alternativa de propagandas, muitos achavam que haveria uma inundação de telas de promoções nos computadores. Para Al Ries como citado em Bottini (2000), esta projeção para o futuro não se sustentava e por fim não ocorreu. Segundo o autor, na Internet as pessoas têm o controle da situação e não estão dispostas a ler anúncios ou qualquer forma de propaganda ou de publicidade; por se tratar de mídia interativa, o usuário tem o poder de rejeitá-la. Isso não implica que não haverá propaganda na Internet, mas que ela não será mídia tão forte como a televisão.

Al Ries como citado em Bottini (2000) afirma que existe ceticismo das pessoas em relação à propaganda na Internet, pois the falta a credibilidade editorial de uma revista ou de um jornal. O mesmo autor afirma que para promover um produto ou serviço, deve-se inicialmente partir do mundo real e depois utilizar a Internet como canal promocional complementar.

Castells (2001) enfatiza que a utilização da propaganda na Internet motivou a criação de nova linguagem, com formato mais adequado à nova mídia interativa. Uma das oportunidades geradas pela Internet é a propaganda many-to-many, de muitos para muitos (Castells, 2001). Para Dizard (2000), as possibilidades que a Internet oferece, ao mesmo tempo que causa entusiasmo aos profissionais de propaganda e anunciantes, também amedronta pela abrangência e pela incerteza no futuro. Apesar do rápido crescimento da Internet, as empresas de mídia e outros varejistas ainda têm pouca informação sobre os clientes na Internet para direcionar suas estratégias. Ainda segundo o mesmo autor, o mundo caminha 
para uma convergência de mídias; a fronteira entre a mídia tradicional e as novas mídias, está no centro da discussão.

Atualmente já é possível ler o jornal e a revista, conversar com um amigo em tempo real, enviar correspondências, assistir ao noticiário, ouvir músicas e assistir a filmes pela Internet (Karsaklian, 2001). Essa convergência também se reflete na propaganda da Internet, que é resultante da propaganda convencional com o marketing de resposta direta, conforme Figura 2.

\section{Figura 2: A Propaganda na Internet}

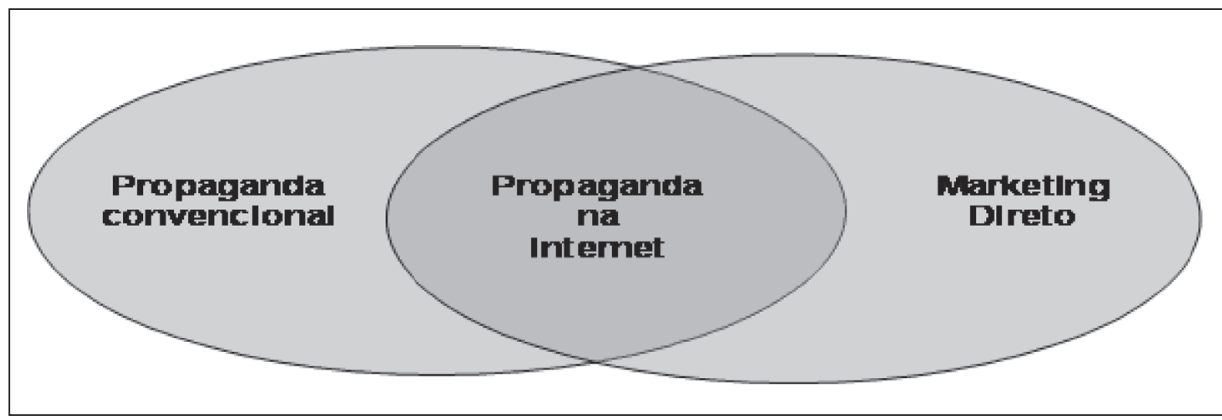

Fonte: The Zeff Group (1999).

Conforme Castro (2000), a Internet é a única mídia que permite combinar o poder da comunicação de massa de emitir uma mensagem e alcançar grande audiência com as possibilidades de interação e feedback. Ainda segundo o mesmo autor, a Internet oferece meios de anunciar produtos, vendê-los, responder a solicitações dos consumidores e finalmente fidelizá-los; os pontos fortes dessa na nova mídia são: a interatividade, flexibilidade, monitoramento e a segmentação.

Churchill e Peter (2000) descrevem algumas vantagens da Internet sobre outras mídias, como por exemplo: as mensagens podem ser personalizadas; não há custo adicional para alcançar o público mundial distribuído; a mensagem pode incluir palavras, figuras, sons e vídeos. Por outro lado, os autores admitem haver alguns limitadores dessa mídia, como estes: nem todos os internautas entendem a mensagem utilizada no anúncio em um website; a qualidade das imagens varia em função do equipamento e da banda disponíveis; a audiência restringe-se a usuários da Internet que têm algum interesse na empresa, no produto ou serviço; na questão da segurança, a Internet pode constituir-se em um canal, para que emails sejam usados para enganar consumidores e prejudicar a imagem das empresas, utilizado principalmente via e-mail. 


\section{Contextualização da Internet no Banco do Brasil}

No setor bancário brasileiro, o Banco do Brasil continua a ser líder em acessos na Internet. Ao final de 2003, o número de clientes habilitados atingiu seis milhões, representando um crescimento de $25 \%$ em comparação ao ano anterior. No mesmo ano, a instituição totalizou aproximadamente um bilhão em transações on-line, o que representa $33,21 \%$ do total em todo o Brasil: $11,79 \%$ caixa; $55 \%$ caixas eletrônicos. Das transações realizadas, 513,3 mil foram feitas por pessoa física e 490,13 mil por pessoa jurídica. Esses números representam aproximadamente um aumento em $60 \%$ nas movimentações dos clientes pessoa física e $68,6 \%$ para pessoas jurídicas em relação ao ano anterior.

Para Lindgren (2001), a Internet é ferramental de grande ajuda na estratégia de marketing de uma empresa, permitindo que ela incremente sua presença e o valor de sua marca no mercado. Laudon e Laudon (2004) enfatizam que a Internet introduziu mudanças significativas na forma como as empresas gerenciam seus negócios. A Internet contribuiu para a redução significativa no custo de desenvolvimento, transmissão e armazenamento de informações, fazendo, ao mesmo tempo, com que a informação se tornasse amplamente disponível. Os autores lembram, ainda, que a Internet possibilitou que muitas atividades de uma empresa, ou mesmo todas, pudessem ser realizadas por meio de um único canal eletrônico.

A Internet é ferramental de grande ajuda na estratégia de marketing, pois permite que a empresa incremente a sua presença e o seu valor de marca no mercado. Nesse contexto, a utilização de websites oferece aos gestores de marketing a oportunidade de comunicarem a missão geral da empresa e da marca, fornecer informações sobre os atributos de produtos e serviços ofertados, assim como relatórios de desempenho e projetos futuros, para uma platéia maior (Lindgren, 2001).

No caso do Banco do Brasil a Internet é um facilitador de construção de relacionamentos duradouros, porquanto, ao disponibilizar serviços e produtos vinte e quatro horas, sete vezes por semana o ano inteiro, permite um contato maior dos clientes com a instituição. O ferramental é ainda uma mídia eletrônica alternativa de promoção e divulgação e um canal a mais de distribuição de produtos e serviços.

A utilização do ferramental tem possibilitado uma redução de idas e vindas dos clientes às agências, assim como redução de custos operacionais, além de associar a imagem do Banco do Brasil à modernidade e automação. Para Laudon e Laudon 
(2004), Lindgreen (2001) e Barbieri (2001), muitas empresas utilizam a Internet como alternativa de comunicação, para manter seus empregados e os seus clientes atualizados sobre as mudanças dos produtos e serviços. Ainda, segundo os autores, a Internet pode servir como canal adicional de distribuição de produtos e serviços com algumas facilidades características deste canal eletrônico, como, por exemplo:

. maior comodidade, segurança e rapidez no serviço on-line;

. redução de filas nos Bancos;

. realização de operações de qualquer lugar, hora ou dia;

. maior segurança e privacidade;

- aquisição de microcomputadores, por meio da disponibilidade de linhas de crédito.

O website do Banco do Brasil é estruturado de forma a facilitar que o cliente encontre, mesmo sem se identificar, soluções para as suas necessidades. Limeira (2003) relembra que a Internet desempenha as funções de meio de informação, comunicação e entretenimento para seus usuários. Dessa forma, para o gestor de marketing, a comunicação com o cliente pelo auto-atendimento pela Internet oferece grande oportunidade. No que diz respeito ao atendimento do cliente, a Internet está mudando a forma de atendimento nas agências do Banco do Brasil, já que está possibilitando uma redução de idas e vindas dos clientes às agências, assim como redução de custos operacionais (telefone e fax), além de associar a imagem de banco à modernidade e automação.

O Banco do Brasil disponibiliza no seu website serviços que reúnem, em um único ambiente: transações, negócios e conteúdos. Destacam-se:

- Gerenciador Financeiro é um serviço desenvolvido para atender a pessoa jurídica que deseja usar a Internet para administrar seu movimento financeiro em um só acesso.

- Auto-Atendimento do Setor Público é uma solução de Internet para os clientes do segmento governo que no primeiro semestre de 2003 registrou 2,1 milhões de transações no valor total de $\mathrm{R} \$ 2,7$ bilhões.

- Agronegócios-e constitui uma solução para os clientes que buscam soluções em agronegócios. Em 2003 esse serviço movimentou R $\$ 2,5$ bilhões, valor $252 \%$ superior ao do ano de 2002. 
. Licitações-e é uma solução que tem por objetivo dar agilidade e transparência nas compras governamentais, por meio da oferta de linhas de crédito para fornecedores e constitui um serviço eletrônico disponibilizado a qualquer órgão governamental a custo zero. As movimentações do Licitações-e ultrapassaram $\mathrm{R}$ \$ 969 milhões em negócios em 2003, sendo que em 2002 o valor foi de $\mathrm{R} \$ 25$ milhões

. Sala Virtual de Negócios Internacionais é uma solução de Internet que permite a realização de negócios pela Internet com redução de custos para exportadores e importadores. No ano de 2003, as operações nessa solução movimentaram US\$996,36 milhões.

- e-cultura é um serviço de distribuição de conteúdo, no qual o Banco do Brasil disponibiliza pela Internet artigos, entrevistas, galeria de fotos, links, notícias e reportagens sobre a cultura do Brasil.

Com a Internet foi possível também que o Banco do Brasil criasse novo serviço. Lançada em 2001, a contratação de câmbio pela Internet constitui outra inovação em serviços da instituição. Esse serviço permite a cotação e contratação de operações de câmbio de exportação sem a necessidade de deslocamento do cliente até a agência do banco. O serviço movimentou cerca de US\$ 1 bilhão em 2003 em contratações de câmbio pela Internet. O Banco do Brasil pretende, para 2004, implantar a cotação de contratos de importação também pela Internet.

É pertinente lembrar que a Internet, por ser poderosa fonte de informações, contribui positivamente para o incremento do sistema de informações do Banco do Brasil. As informações colhidas pela Internet nutrem o datawarehouse com dados sobre os hábitos dos clientes, ao realizarem as mais diversas operações que o webpage da instituição permite. As ferramentas de datamining também são utilizadas na Internet. Estas ferramentas permitem monitorar o comportamento dos clientes nas suas ações de aquisições on-line. É possível, dessa forma, gerar perfis de consumo e adicionar informação ao datawarehouse que mais adiante auxiliará os projetos de CRM.

As características interativas das webpages podem ser utilizadas pelos gestores de marketing no intuito de prender a atenção dos clientes ou para capturar informações específicas sobre seus gostos e interesse. As webpages constituem mecanismo enriquecedor de informações sobre o comportamento do consumidor. Com a utilização de softwares especiais, é possível a empresa monitorar a frequiência de visitas de usuários das webpages e assim obter informações para traçar o perfil do consumidor (Laudon \& Laudon, 2004). 


\section{A Utilização da Internet como Canal Promocional}

Quando a questão é estratégia de promoção, a Internet tornou-se um canal a mais para as ações promocionais do Banco do Brasil. As propagandas pela Internet destinam-se principalmente à divulgação de novos produtos e serviços, à transparência dos negócios, à inclusão digital e à desmistificação do uso da Internet.

A estratégia de propaganda pela Internet do Banco do Brasil inclui a utilização de ferramentas como banners e newsletters para divulgarem seus produtos e serviços, assim como suas ações sociais. É dada maior atenção às newsletters, pois muitos usuários consideraram-nas uma invasão de privacidade. De acordo com Limeira (2003), o e-mail marketing (newsletter), ou melhor, a mala direta eletrônica, é nova ferramenta de comunicação e de marketing direto com uso crescente pelas empresas, uma vez que o serviço mais utilizado pelos internautas é o e-mail.

É imperativo para as empresas que, ao utilizar a Internet como um canal a mais de promoção, projetem seus websites de maneira que os clientes possam ver rapidamente o valor de se visitar um website. Para Limeira (2003), a realização e promoção de concursos com premiação são exemplos de atrativos que sensibilizam o cliente a retornar ao website de uma empresa.

Nesse contexto o Banco no Brasil investiu em um rápido lançamento de promoções com diferenciais exclusivos para o uso do canal eletrônico. É o caso das promoções: Seguro Ouro Auto, com forte incentivo para a renovação de seguros pela Internet; a promoção Clube Ouro (Programa de Prêmios e Descontos do Banco do Brasil), que sorteou mais de cem carros e teve boa parte das inscrições realizadas pelo website do Banco do Brasil; e a Promoção bb.com.br, que visou incentivar diretamente a realização de transações bancárias pela Internet.

No ano de 2003, o Banco do Brasil registrou crescimento de $70 \%$ nas renovações do seguro Ouro Auto comparados a 2002. Com o objetivo de incentivar a venda do seguro 'Ouro Auto via Internet', o Banco do Brasil passou a oferecer o documentário em DVD 'Carro Mania', produzido pelo Discovery Channel. O resultado dessa iniciativa foi que 5.884 clientes contrataram ou renovaram seu seguro via Internet e todos receberam o DVD 'Carro Mania' junto com a apólice.

Outra forma de promoção utilizada pelo Banco do Brasil na Internet visa a dar transparência aos negócios, por meio da divulgação de suas atividade e ações para o público em geral. No website, o cliente pode acessar as demonstrações de resultado, balanço social, relatórios da administração, relatório institucional, relatórios de gestão, assim como acesso de apresentações de arquivos de áudio 
de reuniões e seminários com acionistas e ações sociais. Esse serviço possibilita ao Banco do Brasil manter um contato diferenciado com seus clientes. Há mesmo uma estratégia utilizada para estimular os clientes a conhecerem o website da instituição: distribuir quiosques de acesso à Internet espalhados por algumas agências, assim como o boca a boca dos gerentes com clientes e propaganda em massa.

A Internet, como canal promocional, possibilita ainda que o público em geral acompanhe as ações sociais desenvolvidas pela instituição. Este serviço é conhecido como projeto e-cidadania.

O projeto e-cidadania é programa comprometido com as causas sociais. Tem por objetivo disseminar por meio da Internet: experiências e conhecimentos; articular tecnologias sociais capazes de resolver questões nas áreas de educação, saúde, assistência social, ciência e tecnologia, cultura e assistência a comunidades urbano-rurais.

Conforme Laudon e Laudon (2004), as características interativas dos websites podem ser utilizadas pelos gestores de marketing no intuito de prender a atenção dos clientes ou para capturar informações específicas sobre seus gostos e interesse. Os websites constituem mecanismo enriquecedor de informações sobre o comportamento do consumidor. Ainda segundo os mesmos autores, com a utilização de softwares especiais, é possível a empresa monitorar a frequiência de visitas de usuários das websites e assim obter informações para traçar o perfil do consumidor e definir estratégias de promoção focadas nas necessidades e atributos que os clientes valorizam nos produtos e serviços em processo de aquisição.

É pertinente, portanto, lembrar que a Internet por ser uma poderosa fonte de informações, contribui positivamente para o incremento do sistema de informações de marketing do Banco do Brasil. As informações colhidas pela Internet nutrem o datawarehouse com dados sobre o comportamento dos clientes ao realizarem as mais diversas operações que o website da instituição possibilita. Isso permite melhor utilização dos sistemas de CRM do banco, na manutenção de suas carteiras de clientes, e até mesmo ações promocionais.

\section{Considerações Finais}

A Internet é fenômeno ainda muito recente, principalmente no mundo dos negócios. E, embora já se notem alguns naufrágios decorrentes de ilusões e negócios mal estruturados, é indubitável que a rede mundial de computadores 
representa ferramenta interessante para os negócios, seja como meio para o desenvolvimento de comércio eletrônico, seja como veículo integrador de mídias.

O ferramental Internet, quando utilizado, altera o ambiente de marketing, ao criar empresas virtuais, além de bens e serviços, e ao possibilitar o surgimento de processos de marketing mais eficientes e eficazes, o que incrementa todos os aspectos dos negócios contemporâneos, gerando novos desafios. No entanto é preciso lembrar que os vários setores e as várias empresas se adaptam de maneira diferente; no caso do setor bancário, as aplicações de Internet ganham dimensão significativa, devido às suas características e às dos seus produtos e clientes.

Para Albertin (1998), a utilização da Internet pode ser de imensa utilidade para os negócios bancários, por ser canal de comunicação muito versátil e independente de barreiras geográficas. Conforme Limeira (2003), os bens e serviços comercializados por meio da Internet podem não sofrer muitas alterações com respeito a atributos físicos, mas a Internet pode facilitar a customização e incrementar suas características de produto ampliado, ao tornar mais acessível uma série de serviços. A própria webpage da empresa pode passar a fazer parte do produto, ao tornar disponíveis informações e serviços complementares ao produto vendido, devendo proporcionar uma experiência agradável ao visitante. Itens como, garantia da segurança das transações e privacidade das informações, até então tratadas com pouca relevância no mundo físico, começam a despontar como diferenciais dos produtos oferecidos.

O marketing pela Internet, sob certos aspectos, pode superar determinados canais tradicionais, como lojas de fábrica, ou substituir os intermediários mais eficientemente. Os distribuidores estão sendo forçados a ajustar suas estratégias e incluir transações on-line em suas operações. Contudo isso não autoriza a se acreditar na extinção total dos intermediários, em virtude de não ser possível negligenciar os clientes dos estabelecimentos tradicionais, os das lojas do tipo "tijolo e argamassa". Na prática, a coexistência de ambos os tipos de operações pode trazer ganhos para ambos, sendo complementares entre si, desde que as estratégias estejam em consonância com cada ambiente.

A Internet pode atuar como canal de promoção para produtos e serviços por ela ofertados, com muitas aplicações, especialmente em marketing direto, devido aos recursos multimídia e às sofisticadas ferramentas para análise de perfis e hábitos de consumo e gerenciamento de clientes. Porém a própria empresa precisa de meios para se promover, como qualquer outra, com uma diferença: no mundo físico, o cliente vê a loja e pode se sentir tentado a visitá-la; já o website na Internet depende da memorização de um endereço ou de mecanismos de busca para se saber de sua existência. 
No caso da Instituição financeira Banco do Brasil, a utilização do ferramental Internet está desenvolvendo-se em processo contínuo e crescente. Como ponto de venda, a Internet já alcançou destaque na estratégia de marketing, em virtude da sua abrangência geográfica e disponibilidade temporal. Em relação às ações de promoção, a Internet tem papel fundamental no negócio do Banco do Brasil. Seja como mídia alternativa de divulgação de produtos e serviços, seja como canal eletrônico de contato com os clientes. A Internet constitui, ainda, para o Banco do Brasil, um mecanismo pelo qual a instituição pode monitorar o comportamento de clientes e concorrentes e, assim, adicionar valor às suas estratégias promocionais.

\section{Artigo recebido em 30.03.2004. Aprovado em 03.07.2004.}

\section{RefERÊNCIAS BibliográficAS}

Albertin, L. A. (1998, janeiro/ março). Comércio Eletrônico: benefícios e aspectos de sua aplicação. Revista de Administração de Empresas, 38(1), 52-63.

Barbieri, C. (2001).

$B I$ - business intelligence modelagem \& tecnologia (2a ed.). Rio de Janeiro: Excel Books do Brasil Editora.

Bishop, B. (2000).

Strategic marketing for the digital age (3rd ed.). McGraw-Hill Companies.

Bonoma, T. V. (1985, May).

Case research in marketing: opportunities, problems, and process. Journal of Marketin of Research, 22(issue 2), 7.

Bottini, A. (2000, dezembro).

Al Ries - guru do marketing defende marca nova para web e ataca convergência. Revista Meiodigital, p. 18 .
Boone, L. E. \&

Kurtz, D. L. (2001).

Contemporary Marketing (10th ed.).

Orlando: Harcourt CollegePublishers.

Bransky, R. M. (1999).

Desafios da venda direta ao consumidor pela Internet. In: C. F. Angelo, \& J. A. G. Silveira. Varejo competitivo, (Vol. 4). São Paulo: Atlas.

Castells, M. (2001).

Sociedade em Rede: a era da informação, economia, sociedade e cultura (Vol.1). Rio de Janeiro: Paz e Terra.

Castro, A. (2000).

Propaganda e mídia digital: a web como a grande mídia do presente. Editora Qualitymark. Rio de Janeiro.

Chleba, M. (2000).

Marketing digital: novas tecnologias \& novos modelos de negócio (2a ed.). São Paulo: Futura. 
Churchill, G. A., Jr., \&

Peter, J. P. (2000).

Marketing: criando valor para o cliente. São Paulo: Saraiva.

Cobra, M. (1993).

Marketing competitivo. São Paulo: Atlas.

Dizard, W., Jr. (2000).

A nova mídia: a comunicação de massa na era da informação (2a ed.). Rio de Janeiro: Jorge Zahar.

Drucker, P. (2000, janeiro/fevereiro).

Além da revolução da informação. HSM Management, 18, pp. 48-55.

El-Check (1991).

Marketing básico para pequenos e médios empresários (2a ed.). Petrópolis: Vozes.

Farina, S., \&

Becker, F. S. U. (1997).

Apresentação de trabalhos escolares (16a ed.). Porto Alegre: Multilivro.

Karsaklian, E. (2001).

Cybermarketing. São Paulo: Atlas.

Kotler, P., \&

Armstrong, G. (2002).

Administração de marketing: a edição do novo milênio (10th ed.). Prentice Hall.

Kosiur, D. (1997).

Understanding Electronic Commerce. Washington:Microsoft Press.

Las Casas (1992).

Markenting de varejo. São Paulo: Atlas.
Laudon, K. C. \&

Laudon, J. P. (2004).

Sistemas de informação gerenciais (5th ed.). São Paulo: Prentice Hall.

Limeira, T. M. V. (2003). E-Marketing: o marketing na internet com casos brasileiros. São Paulo: Saraiva.

Lindgren, J. H. (2001).

Marketing na Internet. In: M. R. Czinkota, Marketing - as melhores práticas (pp. 464-483). Porto Alegre: Bookman.

Mccarthy, J. (1996).

Basic marketing - a global managerial approach. USA: McGraw-Hill.

Mcdonald, M., \&

Dunbar, I. (1995).

Market segmentation: a step-by-step approach to creating profitable market segments. London: Macmillan Business.

Morris, M. J. (1991).

Iniciando uma pequena organização com sucess. São Paulo: Makron Books.

Neil Borden (1953).

"The Concept of Marketing Mix". In: M. E. Bem, K. C. Keith, \& P. M. Michael, (Eds.). Marketing Classics (5th ed., pp.421-428). Upper Saddle River, NJ: Prentice-Hall.

Silva, J. A. R., \&

Oliveira, L. C. V. de. (1997).

O marketing na internet. BR: uma avaliação da presença empresarial na World Wide Web. Anais do Encontro Nacional dos Programas de PósGraduação em Administração, Rio das Pedras, RJ, 21. 
Telles, R. (2003).

$B 2 B$ - marketing empresarial São Paulo: Saraiva.

The Zeff Group (1999).

Zeff, Robbin. The marketing and Internet Online. Retrieved January 23, 2004, from http://www.zeff.com

Turban, E.,

Lee, E.,

King, D., \&

Chung, H. M. (2000).

Electronic commerce: a managerial perspective. New Jersey: Prentice Hall.
Waterschoot, W. V. (1992, October).

The 4P classification of the marketing mix reviwebsited. Journal of Marketing, 56, pp. 32-27.

Windham L. (1999).

Dead ahead: the web dilemma and the new rules of business. New York: Allworth Press. 